\title{
East African rainfall seasonality based on modulated annual cycle (MAC)
}

\author{
Zablone Owiti ${ }^{1,2 \star}$ and Weijun $\mathrm{Zhu}^{1}$ \\ ${ }^{1}$ College of Atmospheric Science, Nanjing University of Information, Science and Technology, 219 Ning Liu Rd., \\ Nanjing, Jiangsu, 210044, P.R. China. \\ ${ }^{2}$ National Council for Science and Technology, P.O. Box 30623-00100, Nairobi, Kenya.
}

Accepted 04 May, 2012

\begin{abstract}
The spatial and temporal variability of East African rainfall seasonal cycle is investigated based on modulated annual cycle (MAC). Ensemble empirical mode decomposition (EEMD) is used to extract MAC from monthly data for the period 1900 to 2008. The MAC is given by year-to-year changes in annual and semi-annual components. Results show that MAC account for between 45 to $80 \%$ proportion of rainfall variability. Spatial structure of MAC shows that it captures the north-south (equatorial) pattern for annual (semi-annual) mode with explained variance of $54 \%(22 \%)$. The spatial structure of MAC further reveals that the seasonality of rainfall over the whole region does not follow the north/south classical scheme where the semi-annual component dominates the equatorial while the annual component dominates areas relatively far from the equator. MAC amplitude tends to be high during anomalous rainfall indicating that the impact of major climate processes that produce seasonal cycle are amplified or suppressed by interannual to longer timescale climate variability modes. This study has shown variability in the seasonal cycle of East African rainfall on interannual-to-longer time scales, which should be considered in studies on variability of rainfall and in seasonal- to-longer time scale prediction of rainfall over the region.
\end{abstract}

Key words: East Africa, rainfall variability, modulated annual cycle, empirical mode decomposition.

\section{INTRODUCTION}

Major sectors of East African region economy like agriculture, heavily depend on the availability of water, and therefore, directly or indirectly, on rainfall. The region experiences and is sensitive to large climate fluctuations in terms of floods and droughts which have resulted to disasters which the inhabitants have only marginally been able to cope with.

In recent years, East Africa has suffered frequent episodes of both excessive (Webster et al., 1999; Latif et al., 1999) and deficient rainfall (Hastenrath et al., 2007) which had impacted negatively on the economy. The drought of 2011, over most parts of the region was one of

\footnotetext{
${ }^{*}$ Corresponding author. E-mail: zowiti@ncst.go.ke or zablonowiti@yahoo.com. Tel: (+86) 18750919042. Fax: (+86) 2558699848.
}

the worst in 60 years. Another example is the extreme rainfall event of 1961 that led to disastrous floods in the region.

Shongwe et al. (2011) have shown that that the frequency disasters related to anomalously strong rainfall has increased over east Africa based on their analysis of data from the International Disaster Database EM-DAT (http://www.em-dat.net/).

Past studies East African climate variability (Indeje et al., 2000; Mutai and Ward 2000; Schreck and Semazzi, 2004) have shown that the variability is caused by different factors on different time-scales. However, few studies have examined the coherent temporal modes of East African rainfall variability and their association with the large scale atmospheric and oceanic patterns on individual timescales.

Bowden and Semazzi (2007) for example, noted that previous studies of intraseasonal variability focus on case 
studies of wet or dry years linked with the El NiñoSouthern Oscillation (ENSO) phenomenon.

Segele et al. (2009) studied the seasonal to interannual variability of Ethiopia/Horn of Africa monsoon rainfall associated with wavelet filtered large-scale atmospheric circulation and global sea surface temperatures (SST). This study was confined to the northern Horn of African region and was based on the summer monsoon season (July to September).

Seasonal cycle is the largest climate signal; however its variability has been overlooked as a climate diagnostic. It is often removed (by considering anomalies from it) in studies concerning climate variability or change. However, previous studies, for example Pezzulli et al. (2005), Shen et al. (2005), and Wu et al. (2008) have shown that the seasonal cycle can contain amplitude-frequency modulation due to the nonlinearity of the climate system.

Further, inter-annual variations in the seasonal cycle have been observed in climate time series (Thompson, 1999; Bograd et al., 2002; Whitfield et al., 2002) and deserve more careful attention. Moreover, under a changing climate, the annual cycle is expected to vary and thus the observed increasing intensity of global warming in recent years could significantly offset the subtle balance among the various climatological sources of climate variability over the region. For example, in the period 1996 to 2005; 9 out of the 10 years are among the years with the highest annual temperature on record prior to the most recent Intergovernmental Panel on Climate Change report (IPPC, 2007). Knowledge of variability of rainfall seasonal cycle is therefore an important component in the understanding of climate variability.

If various forcings of seasonal variability could be isolated, then it may be easier to understand the longer term variability such as inter-annual and decadal oscillations in a climate variable. Indeed, a description of the seasonal cycle of rainfall also allows for the dominant seasonal signal to be removed, to give a background for empirical analysis of longer time scale cycles fed by ocean-atmosphere dynamics to improve rainfall monitoring and prediction.

Over East Africa, few studies have examined the spatial and temporal variability of the seasonality of rainfall based on inter-annually varying seasonal cycle. While a general understanding of the geographic patterns of seasonal distribution of East African rainfall climatology have been provided in previous studies (Nicholson, 1996; Indeje et al., 2000), it is also important to examine if there is temporal variability in rainfall annual cycle.This information can be utilized in validation of general circulation model (GCM) simulation of rainfall annual cycle over the region. Moreover, the previous cited studies used multi-stations averaged data to study the annual cycle evolution of rainfall and delineate the region into homogeneous zones.

In this study, we use an alternative dynamic annual cycle that have been proposed by Wu et al. (2008). It consists of modulated annual cycle (MAC) that is modulated in phase and amplitude with interannual variability expressed in terms of these modulations, with respect to a fixed annual cycle. The ensemble empirical mode decomposition (EEMD) (Zhouhua and Huang, 2004; Wu and Huang, 2009), which is an improvement of the original empirical mode decomposition (EMD) method (Huang et al., 1998), is used to extract MAC from monthly rainfall series. EEMD is an adoptive decomposition technique that can decompose nonlinear and nonstationary complicated signal time series into finite quasiperiod components with frequencies.

In this paper, we contribute to the advancement of understanding East African rainfall variability by showing that the modulated annual cycle of rainfall captures the rainfall regimes over the region and that there is variability seasonality of rainfall over the region.

\section{DATA AND METHODS}

Like the rest of Africa, East Africa continues to experience some difficulties with the availability of long-time climate data (Camberlin and Philippon, 2002). Furthermore, the available data are also riddled with numerous gaps in both space and time. These limitations in the quantity and quality of in situ observations impose substantial constraints on diagnostic studies of the regional climate (rainfall) variability. Available are sparse surface observations whose number has tremendously reduced over time. Proxy rainfall datasets have therefore been used in the region in studies where spatial resolution and study period length are of importance.

In this study, Version 2.01 of the University of Delaware rainfall gridded data (Willmott and Matsuura, 2009) was used. The data, gridded at $0.5 \times 0.5^{\circ}$ resolution is land only rain-gauge based precipitation and comprises of 109 years (1900 to 2008) of continuous monthly data (http://jisao.washington.edu/data/ud/). The data has the advantage of being available at higher resolution and longer period of time compared to other gridded data sets.

Further, the University of Delaware dataset benefits from the inclusion of Sharon Nicholson's African gauge data (Nicholson, 2001) for 1950 to 1996 (Parker et al., 2011). The gauge dataset contains a large number of gauges that have not been included in other datasets. A complete description of the data was provided by the Centre of Climate Research Department, University of Delaware webpage:

http://climate.geog.udel.edu/ climate/html_pages/Global2_Ts_2009 /README.global_p_ts_2009.html.

We derived monthly rainfall series from the $0.5 \times 0.5^{\circ}$ gridded data averaged on $2 \times 2^{\circ}$ grids instead of using individual grid cell of the original data to reduce the effect of diverse means, localized climate regimes and the randomness of convective processes reflected in individual station/cell totals over the region (Indeje et al., 2000). The grid-boxes over which the data were averaged are provided in Figure 1a.

\section{Empirical mode decomposition (EMD)}

Empirical mode decomposition (EMD) was introduced by Huang et al. (1998), as an alternative approach to traditional methods for analyzing time series such as wavelets or Fourier methods. The EMD method is different from Fourier and wavelet transforms because it handles nonlinear and non-stationary signals.

The Fourier transform (FFT), which uses basis functions that are 

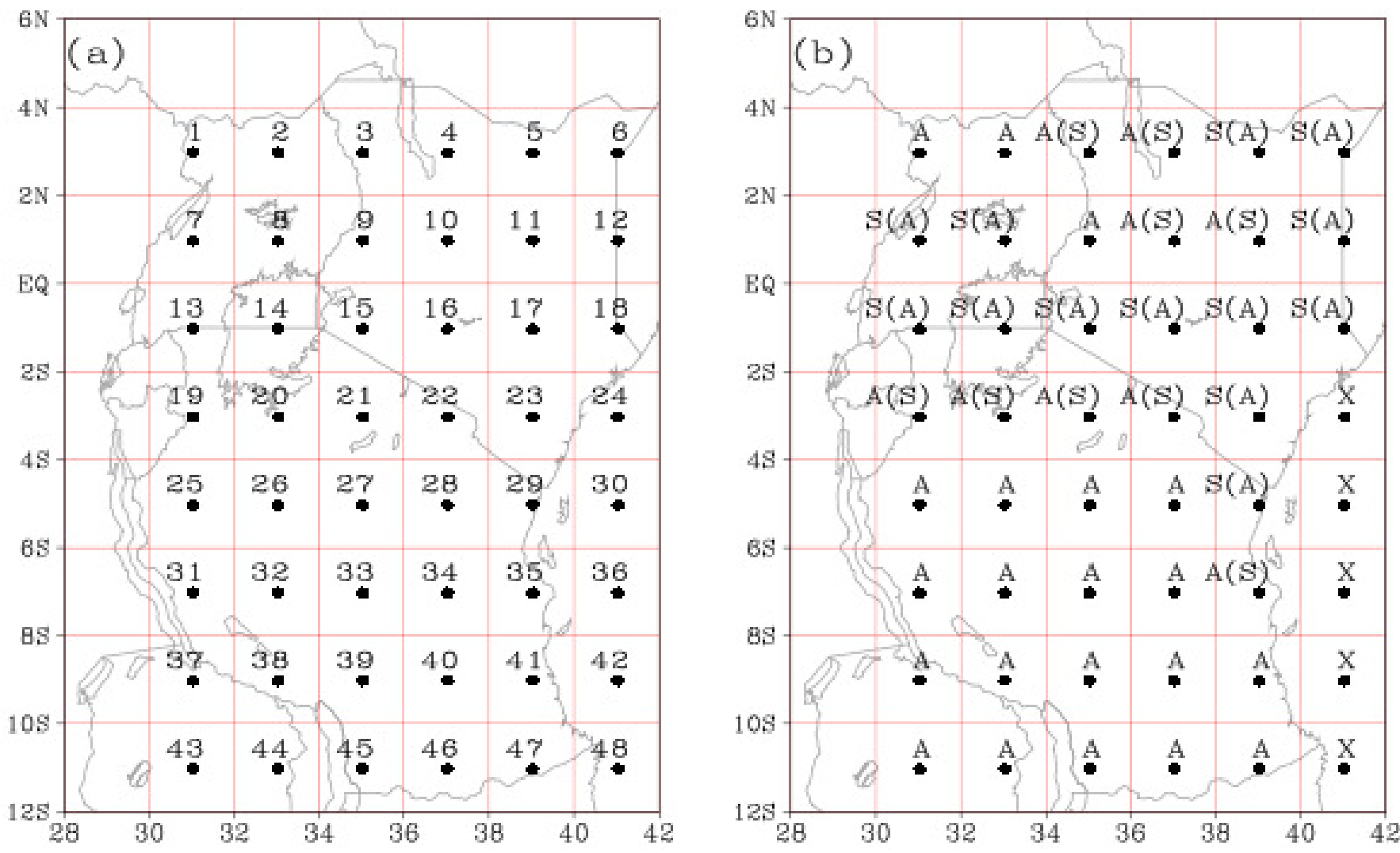

Figure 1. (a) Center locations (marked with dots) of the $2 \times 2^{\circ}$ grids over which the $0.5 \times 0.5^{\circ}$ gridded rainfall are averaged. (b) The dominant component of seasonality at each grid point based on spectral power analysis of the seasonal cycle components extracted by EEMD. A (S) denotes annual (semi-annual) cycle component dominates. $A(S) / S(A)$ indicate that the annual/semi-annual component dominates in locations where both components co-exist. Grid boxes marked $x$ were omitted in the analysis due to lack of data over the Ocean areas.

sine and cosine functions, is designed to work with linear and stationary signals. The amplitudes and frequencies of each basis function are time-independent. Therefore, Fourier analysis is a global analysis, which can describe the frequency content of a signal and works well when the input signal is linear and stationary (Qian, 2002). However, the method is unable to characterize processes that change frequency over time. The wavelet transform, on the other hand, is well suited to handle non-stationary data but poor at processing nonlinear data.

Since the variations in climate variables are complex non-linear and non-stationary in nature, EMD is suited in their analysis. EMD coupled with the Hilbert transform has been shown to work better in depicting the local time scale instantaneous frequencies than wavelet and FFT (Huang et al., 1998). The EMD is an adaptive decomposition technique that can decompose nonlinear and nonstationary complicated signal time series into a definite number of components with different frequencies. These components are called intrinsic mode functions (IMFs). The IMFs have well-behaved Hilbert-Huang transforms from which instantaneous frequencies and amplitudes can be calculated. The key idea of EMD is to locally decompose data $y(t)$ into oscillatory components (IMFs). It considers the signal as a superposition of oscillatory components, which are extracted from upper and lower envelopes. The IMFs are fully data-driven, easy to implement and does not use any analyzed predetermined transform.

The essential procedure is to locally identify the most rapid oscillations in the signal, defined as a waveform interpolating interwoven local maxima and minima. The algorithm for the extraction of IMFs from a given time series $y(t)$ data called sifting consists of the following steps (Huang et al.,1998):

1. Initialize the residue

, set

, and $i=1$; the index of IMF $k=1$.

2. Construct the lower minima, and the upper maxima, envelopes of the signal by the cubic spline method.

3. Calculate the mean values by averaging the upper and lower envelopes. Set

4. Subtract the mean from the original signal:

and

$i=i+1$, and steps (1) to (4) are repeated until becomes an IMF. If so, the $k$ th IMF is given by

An IMF satisfies the following two properties. First, the upper and lower envelopes are symmetric and second, the number of zero-crossings and the number of extremum are equal or differ at most by one.

5. Update residue

This residual component is treated as a new data and subjected to the process described previously to calculate the next

6 . Repeat the foregoing steps until the final residual component $r(t)$ becomes monotone.

The advantage of this method is that the oscillatory modes, which are generated, are derived directly from the data, without any reference to a predetermined dictionary of functions. A one-dimensional discrete signal time series $y(t)$, after being decomposed by EMD method, can therefore be represented with the following 
form:

$$
y(t)=\sum_{k=1}^{K} I M F_{k}(t)+r(t)
$$

Where IMF is the Kth mode of the signal time series, and $r$ is the residual non-linear trend. The time series $y(t)$ can therefore be separated into:

$$
y(t)=T(t)+I(t)+S(t)+H(t)
$$

Where the different components are trend $(T)$, interannual $(I)$, seasonal components $(S)$, and higher frequency $(H)$. Each component is obtained by summing the IMFs that exhibit its frequency. The time scale of each IMF is determined by various combinations of the critical points defined as all the union of the zero-crossings and extrema of an IMF. The longest and the most physical local time scale is the full wavelength: from one maximum (minimum) to the next maximum (minimum) or from one up (down) zero-crossing to the next up (down) zero-crossing.

The EMD method as originally proposed suffered a difficulty of mode mixing, defined as any IMF having large disparity in time scales. The ensemble empirical mode decomposition (EEMD), a variant of the EMD algorithm, which is more stable and minimizes modes mixing (Niazyet al., 2009), was introduced by Zhaohua and Huang (2004) to resolve that shortcoming.

EEMD is a modification of the basic EMD with added white noise to the data at the beginning. Through the ensemble of many trials with different realization of white noises, the final ensemble would not suffer the mode mixing, because the white noise contains all the scales. By adding the white noise, the scale separation is guaranteed by the added noise.

The effects of the added noise on the resulting decomposition would be canceled out through the ensemble procedure. The principle is to add $N$ realizations of Gaussian white noise to the signal $y(t)$ in order to obtain $N$ noisy pseudo signals. Then, EMD algorithm is applied to each signal $y(I), i=1, \ldots, N$. The IMFs vector obtained through each EMD decomposition of $y(i)(t)$, where $K(I), i=$ $1, \ldots, N$ is the number of IMFs.

Finally, the EEMD IMFs (IMFk) decompositions is obtained by averaging corresponding EMD IMFs derived from each signal $y(i)(t)$. The Matlab implementation of the EEMD algorithm was used in this study. The code can be retrieved at the Research Centre for Adaptive Data Analysis (RCADA) webpage: http:// rcada.ncu.edu.tw/research1.htm.

Detailed procedure for using EEMD to extract MAC of a climate variable is provided by Wu et al. (2008) and Qian et al. (2010). The capability and the advantage of using the EMD/EEMD method in extracting the annual cycle component, which has strong amplitude-frequency modulation, from a climate variable have been validated through analyzing synthetic data, monthly SST data, and daily surface air temperature records (Wu et al., 2008; Qian et al., 2010, 2011).

\section{DATA ANALYSIS AND DISCUSSION}

Since the domain of the study is in equatorial region, MAC is given by the year-to-year changes in the annual and semi-annual components of seasonality in sites where both components exist (Figure 1b). To obtain spatial and temporal structures of the MAC, empirical orthogonal function (EOF) analysis was applied to MAC. To depict the interannual variability of seasonal cycle, the instantaneous amplitude modulation part of MAC was obtained by the Hilbert transform (Huang et al., 1998; Huang and Wu, 2008; Kim and Oh, 2009) of MAC. The temporal variability of the leading MAC amplitude EOFPCs was then evaluated.

For demonstration purposes, the decomposition of rainfall series at grid-box 16 , centered at $1^{\circ} \mathrm{S}, 37^{\circ} \mathrm{E}$ (Figure 1a) is used. The semi-annual and annual components of seasonal cycle reconstructed from the decomposition are provided in Figure 2. The spectral density of the MAC component extracted from grid16 monthly rainfall series (not shown) showed the semiannual component to dominate the seasonality in this location.

Semi-annual oscillation is a common feature in the equatorial belt where the site under consideration here lies. It expresses the two distinctive wet seasons over the region where it is large compared to the annual component. The seasons coincide with the double passage of the ITCZ, which lags behind the overhead sun by 3 to 4 weeks over the region.

The dominant seasonality component at each of the 44 grid-boxes considered is shown in Figure $1 \mathrm{~b}$. In order to eliminate the minor influence of data end effects during the EEMD process (Qian et al., 2010), the first and last years of MAC are excluded in further analyses, leaving the period 1901 to $2007(\mathrm{~N}=1284)$.

\section{Spatial and temporal structures of modulated annual cycle (MAC)}

EEMD allows for computation of proportion of variation in a time series that can be attributed to fluctuations at different time scales. Amount of variance associated with each IMF and the residual along with the average period of each IMF can then be computed. Theoretically, the variance of each IMFs and residue should sum up to the variance of the original series, or a value close to the observed variance when the IMF covariance terms are small.

To examine the nature and importance of the seasonal cycle as a function of geographic location, the proportion of total variance described by MAC at each site over the region is plotted in Figure 3 . It manifests two local maxima in most parts of Tanzania and northern Uganda, with minimum locations over eastern Kenya and a small pocket over western Uganda.

In general, the distribution of this proportion in such greater proportion is found in the southern part of the region and the northern tip of Uganda. South of $3^{\circ} \mathrm{S}$, the proportion is more than $70 \%$ with greater than $80 \%$ in southwestern Tanzania. The grid with the highest proportion of MAC in the total variance is Grid 37 centered at $9^{\circ} \mathrm{S}, 31^{\circ} \mathrm{E}(86 \%)$. 

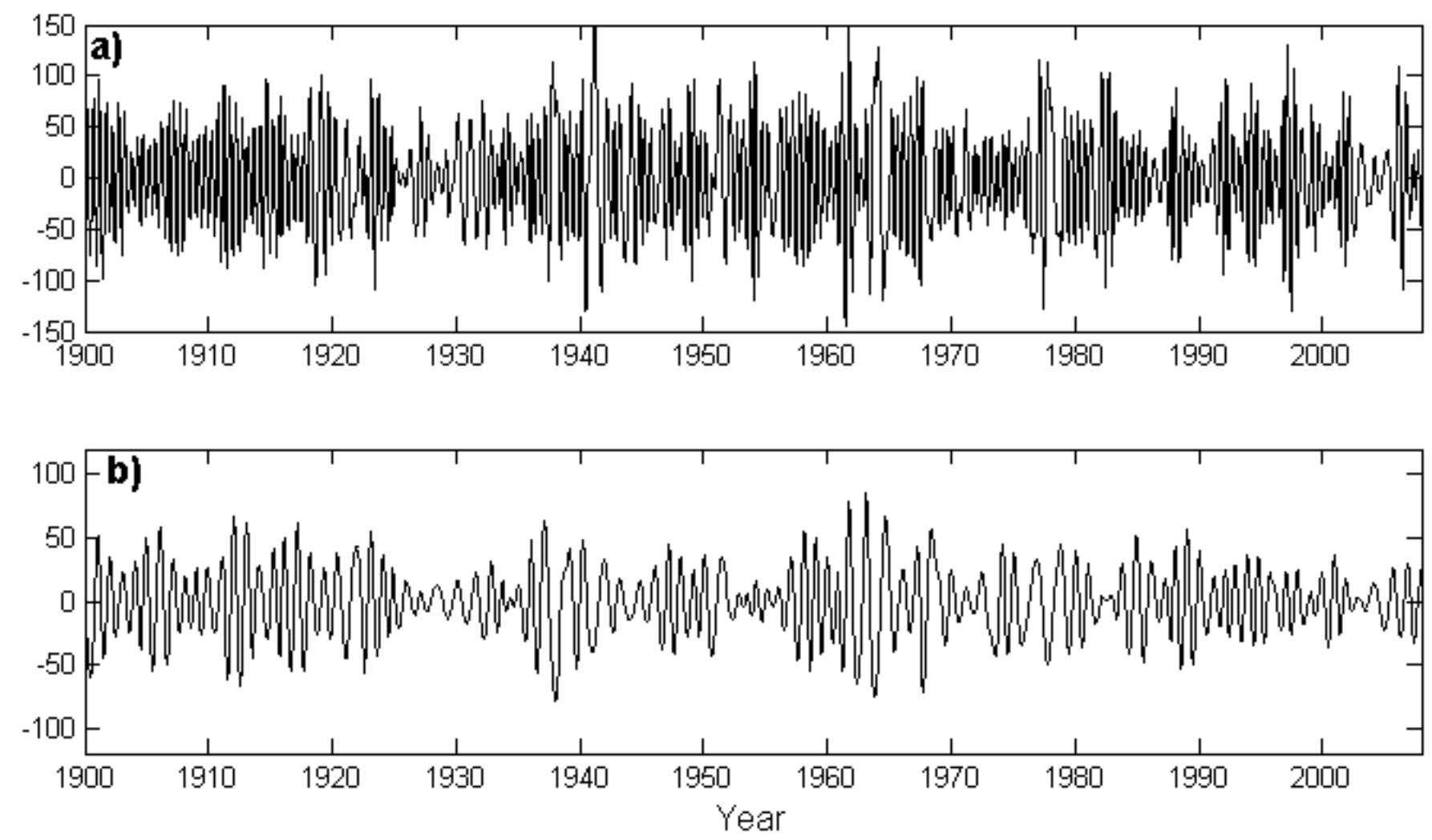

Figure 2. The (a) semi-annual and (b) annual seasonal cycle components reconstructed from the IMFs of EEMD decomposed monthly rainfall at grid 16 centered at $1^{\circ} \mathrm{S}, 37^{\circ} \mathrm{E}$.

In the equatorial zone between $2^{\circ} \mathrm{N}$ and $2^{\circ} \mathrm{S}$, which includes the coastal areas, northern and eastern parts of Kenya, MAC generally accounts for between 45 to $65 \%$ variance. The lowest proportion is $45 \%$ at grid $7\left[1^{\circ} \mathrm{N}\right.$, $\left.31^{\circ} \mathrm{E}\right]$ in western Uganda. These rainfall patterns are controlled by the seasonal migration of the inter-tropical convergence zone (ITCZ) that migrates, north-south, across the region twice a year. The ITCZ thus tends to impose a significant influence on the climatological rainfall and temperature patterns. The ITCZ's influence is credited for defining the bimodal rainfall regime experience in most parts of the region during March to May (MAM) and October to December (OND).

Normally, the passage of ITCZ leads the onset of the two rainy seasons by 3 to 4 weeks, but this may be modulated from season to season by the interactions between the ITCZ and perturbations in the global climate circulation, as well as with changes in the local circulation systems initiated by land surface heterogeneity induced by variable vegetation characteristics, large inland lakes and topography.

In southern Tanzania, unimodal rainfall regime dominates, with the only rainfall season central around southern hemisphere summer (December to February) and hence higher proportion of MAC variance. Parts of
Western Kenya, Western and Northwestern Uganda are however characterized by trimodal regimes since they often receive significant amounts of rainfall during July through September due to penetration of midtropospheric moist westerly flow from the Atlantic Ocean and tropical Congo rainforest air mass (Davies et al., 1985; Mutai et al., 1998).

In the current method of decomposition, the 3 to 4 month periodicities are treated as high frequency modes and therefore not included in the modulated annual cycle (MAC), hence the low proportion of variance is in locations with trimodal regimes.

The first two EOFs of MAC contribute $80 \%$ of rainfall variance. Their spatial loadings and mean time scores are illustrated in Figures 4 and 5, respectively. The mean monthly time scores are based on 107 (1901 to 2007) annual cycle repetitions. The first mode (Figure 4a) exhibits a north-south orientation with two maxima of opposite signs over northern Uganda and most parts of Tanzania (except the coastal areas north of $8^{\circ} \mathrm{S}$ ).

The change-over of the positive and negative loadings have both zonal and meridional orientations. The zonal axis is along the equator and ranges from 20 to $36^{\circ} \mathrm{E}$ while the meridional axis is along $36^{\circ} \mathrm{E}$ and ranges from $4^{\circ} \mathrm{N}$ to the equator. The mean time score (Figure $5 \mathrm{a}$ ) of 


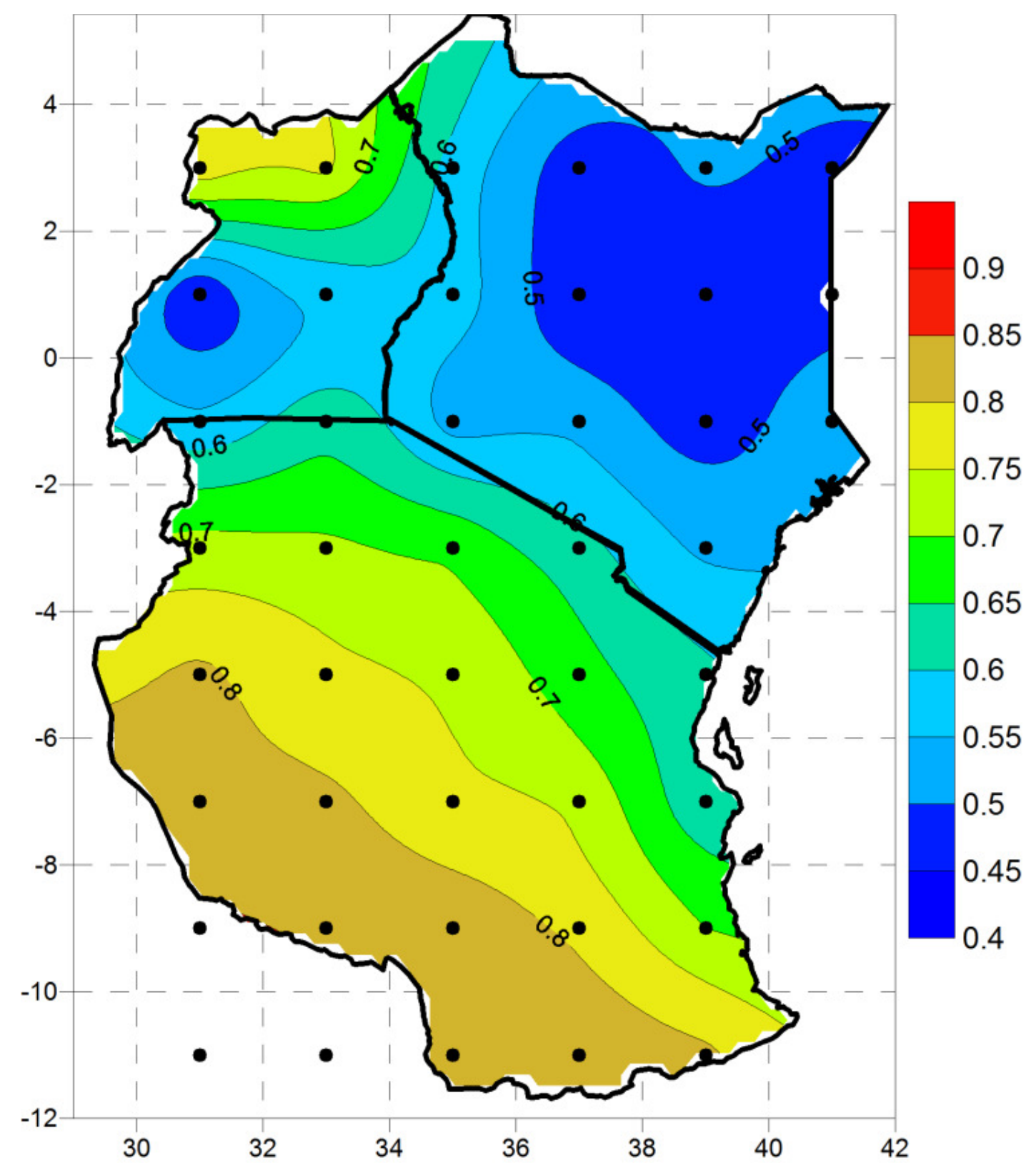

Figure 3. Proportion of total variance of monthly rainfall explained by MAC component. Dots indicate the center of grids analyzed.

this first mode is sinusoidal, with a dip between May to October and a peak between November to April. The standard deviations of the annual cycle are higher during peak season with highest values (2.1) in November and lowest values (0.9) in September. The first mode pattern depicts the north/south locations of the sun during the northern/southern hemisphere summer seasons over the areas which experience unimodal rainfall regime.

Continental climate is distinct in central and southern Tanzania where the positive loadings are strongest. To the east of this region is the coastal strip where climate is influenced by the Ocean via sea/land circulations in most times of the year hence diffused signal of the unimodal regime.

The coastal areas have a unique rainfall patterns that are not necessarily linked to the regular north-south oriented ITCZ passage in the region. The rains in these areas lag the ITCZ by some few weeks due to the influence of near equatorial trough. Long rains, which are much higher in amount generally extends to June. The high amount may be largely due to prevailing wind flow which is orthogonal to the coastline in this season as opposed to the shorts rains season when the winds are more parallel to the coastline (Okoola et al., 2008). 

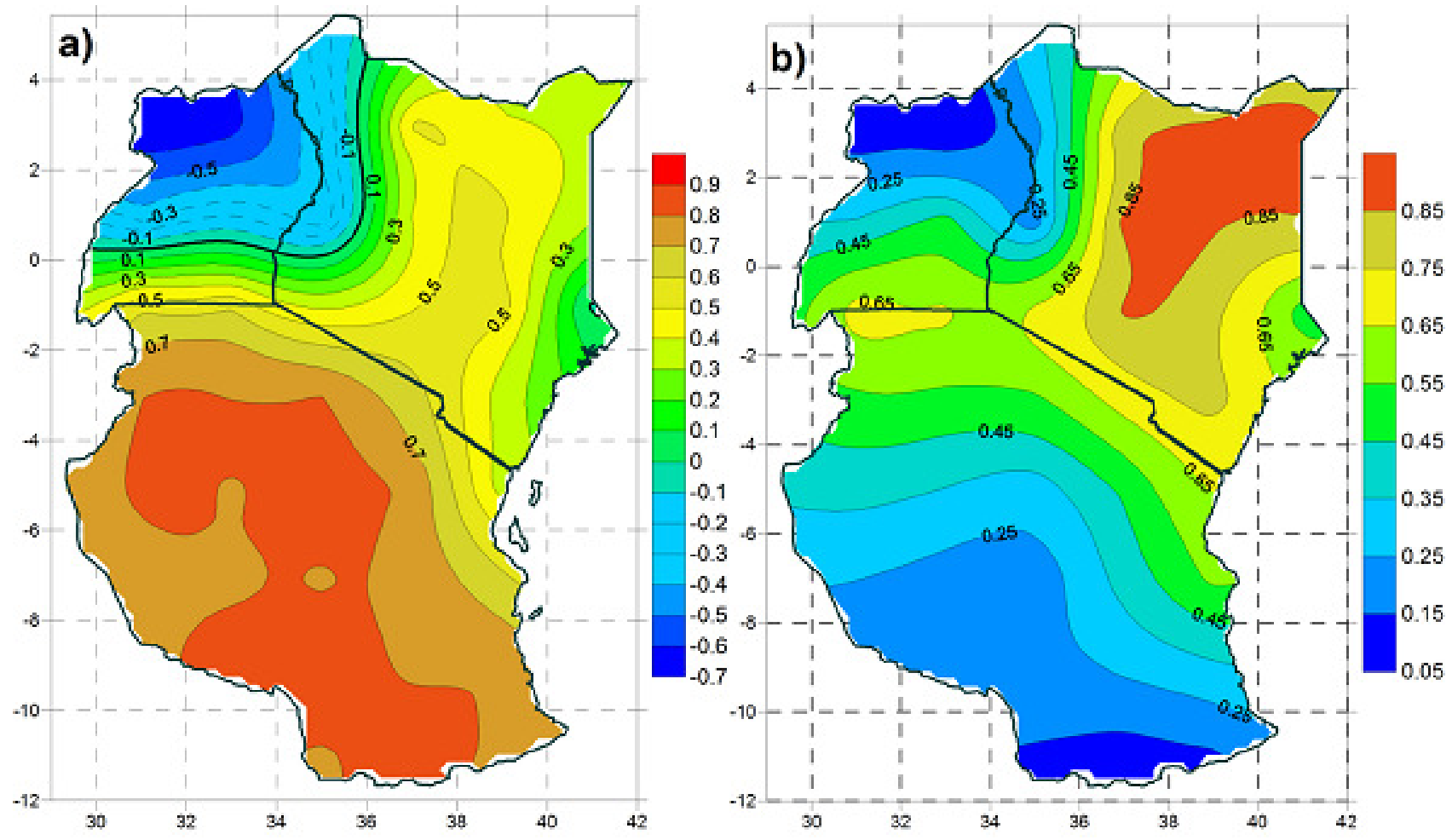

Figure 4. Spatial modes of MAC EOF, (a) leading mode (explains $58 \%$ variance) and (b) second mode (explains $22 \%$ variance).

The first mode, explaining $58 \%$ variance of MAC, expresses the annual component of rainfall seasonality which is strongest in central to southern Tanzania and northwestern tip of Uganda. This north-south dipole pattern expresses the difference in the occurrences of the maxima of the annual component of rainfall seasonality in southern Tanzania and Northwestern Uganda.

The spatial pattern of the second mode, explaining $22 \%$ of MAC variance is shown in Figure $4 b$, while Figure $5 \mathrm{~b}$ illustrates its corresponding mean monthly timescores. Its temporal character (Figure 4d) is distinctly bi-modal with peaks in March to April, locally known as the "Long rains season" and September to November, locally known as the "Short rains season" and minimum around July to August and December to February.

Standard deviation of this second mode is highest/lowest during peak/low seasons. The highest standard deviation (2.3) occurs in November suggesting high rainfall variability during the short-rains season in area where the bi-modal regime is dominant. Similar results are also found in areas dominated by the unimodal rainfall regime in Figure $5 a$.

The loadings of the second mode are generally positive over the region with strongest signals in eastern Kenya, coastal areas of East Africa, southern Uganda and Northern Tanzania.These results agrees with previous studies (Ogallo, 1982; Nyenzi, 1992; Beltrando, 1990; Nicholson, 1996) which have shown that relative to the long (MAM) rains, the short (OND) rains tend to have stronger interannual variability, stronger spatial coherence of rainfall anomalies across a large part of the region.

Statistic significant station to station correlation and seasonal rainfall to annual rainfall correlations during this season have also been found. The dominance of largescale weather systems is responsible for the spatial homogeneity of rainfall during this season. The remaining parts of the region exhibit weak loadings implying weaker (stronger) semi-annual (annual) oscillation of rainfall.

With reference to Figure 3 , it is evident that in the regions of strong seasonality, much of it is from the annual cycle component. From the spatial structures of the MAC modes (Figure 4), it can be concluded that seasonal cycle of rainfall over the whole region does not follow the classical scheme of regular north-south transition of the peak rainfall with a time lag following the overhead sun and the associated ITCZ. This result is corroborated in Figure $1 \mathrm{~b}$ showing dominant modes of seasonality at each grid box. This scenario is only true for the western strip of the region ( 29 to $35^{\circ} \mathrm{E}$ ), where the annual component dominates areas that are north/south of $2^{\circ} \mathrm{N} / \mathrm{S}$ of the equator while the semi-annual component dominate the areas within $1^{\circ}$ north and south of the equator.

Inspection of the time scores of the first 2 modes of MAC whose mean scores are provided in Figure 5 show 

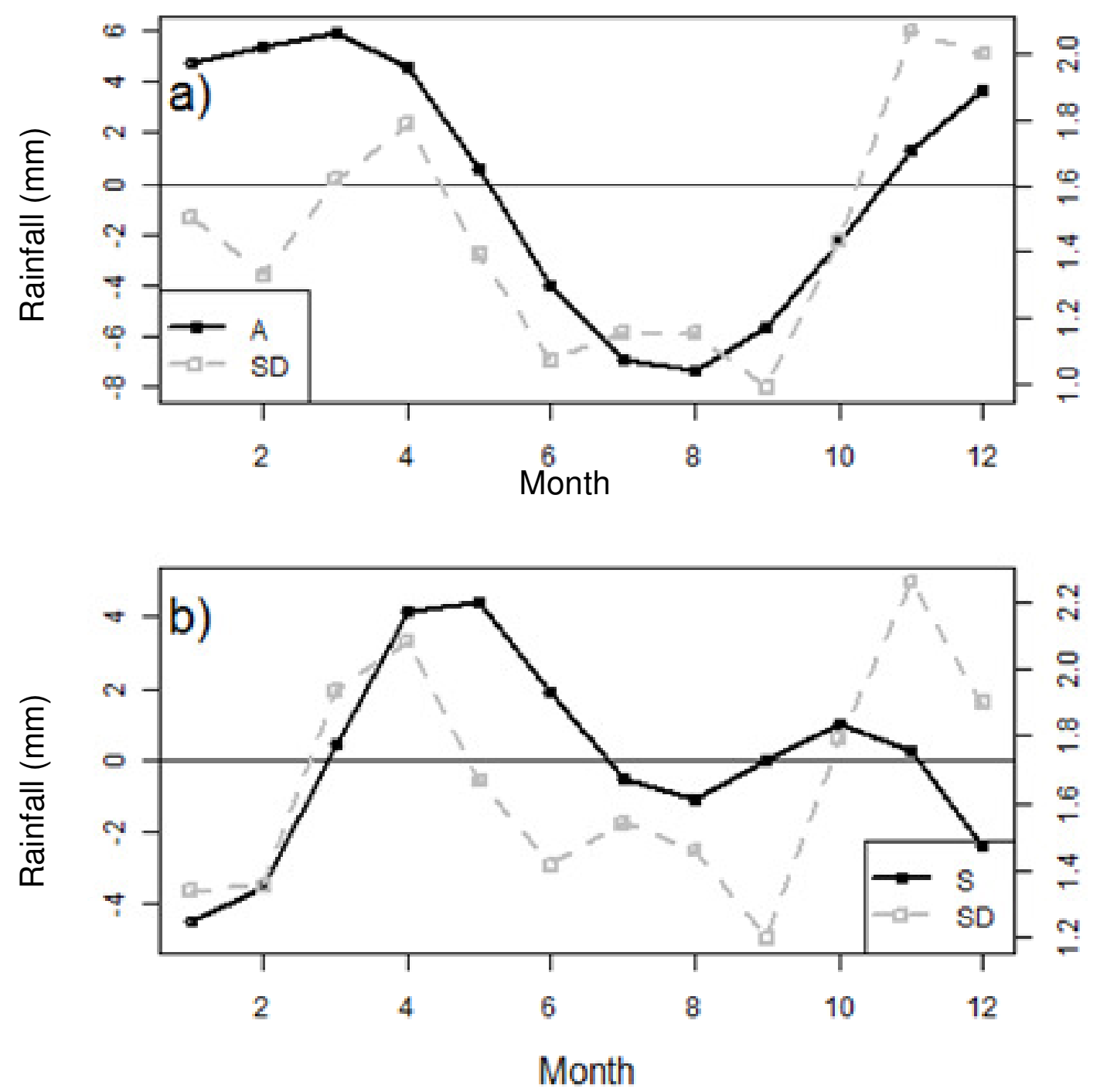

Figure 5. Mean time scores of leading and second mode respectively, based on 107 (a) annual (A) and (b) semi-annual (S) repetitions. The solid line is mean mode, with its scale on the left ordinate, while dashed line is standard deviation (SD), with its scale on the right ordinate.

that the annual component of seasonality is not strictly regular in amplitude. High amplitudes occur around 1905/ 1906, 1916/1917, 1930/1931, 1951, 1961/1962, 1978 and 1997, during which the amplitude is about twice the standard deviation. During some of these years, the region experienced anomalous rainfall.

The extreme rainfall event of 1961 to 1962 was unprecedented in intensity, duration, and extent during the $20^{\text {th }}$ century in the East African region (Conway, 2002) and was triggered by the Indian Ocean Dipole (IOD) mode (Black et al., 2003; Owiti et al., 2008). A similar anomalous event but less in magnitude occurred in 1997, a period when the Indian Ocean dipole (IOD) and EI Niño co-occurred. The anomalous rainfall events in 1905 to 1906 and 1916 to 1917 have also been reported by Conway (2002). These results suggest that the amplitude of seasonal cycle tends to be high/low during anomalous rainfall years.

Further, the mean PC times scores (Figure 5a, b) captures the major rainfall regimes experienced over the region, with mean $\mathrm{PC} 1$ series expressing the unimodal regime over Central and Southern Tanzania and Northwestern Uganda. The two areas however experience peak rainfall in different seasons of the year with southern Tanzania having it peak as shown in Figure 5a during southern hemisphere summer; while northwestern Uganda peaks in northern hemisphere summer that is, the two areas has a dipole rainfall pattern.

The mean PC2 series expresses the bimodal regime over the remaining parts of the region. SVD analysis by Jury and Mpeta (2009) based on under composed monthly rainfall captured only the March to May rainfall 

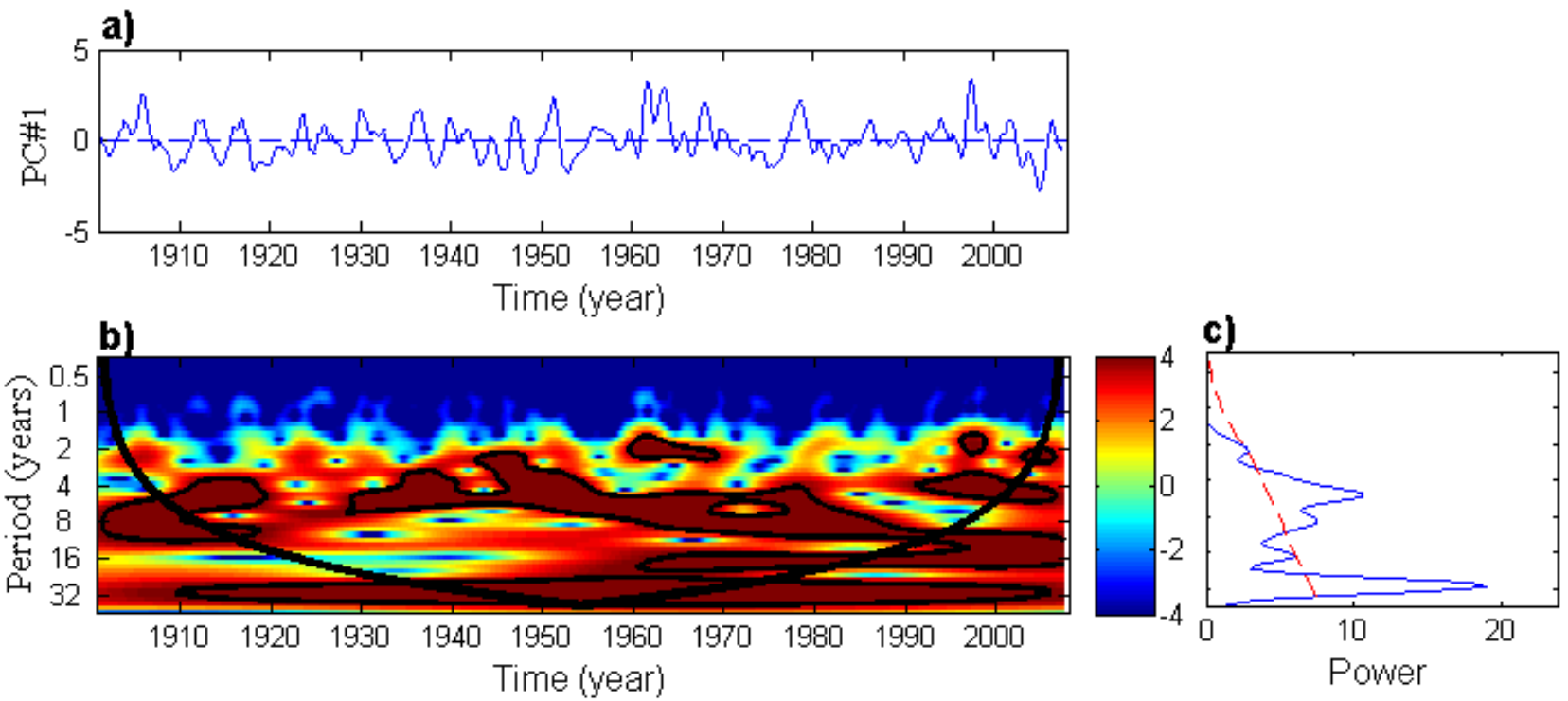

Figure 6. Morlet wavelet of MAC PC1 amplitude for the period 1901 to 2007 (a), its wavelet power spectrum (b) and its global wavelet spectrum. In panel (c) solid line indicates global wavelet power while the dotted line indicates $95 \%$ significant level. Thick contours in (b) enclose area of greater than $95 \%$ for a red-noise process with a lag-1 coefficient of 0.72 (Torrence and Compo, 1998).

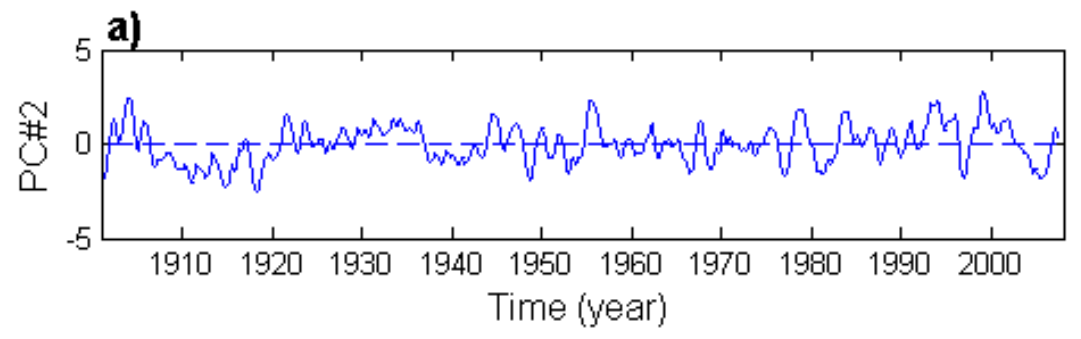

b)

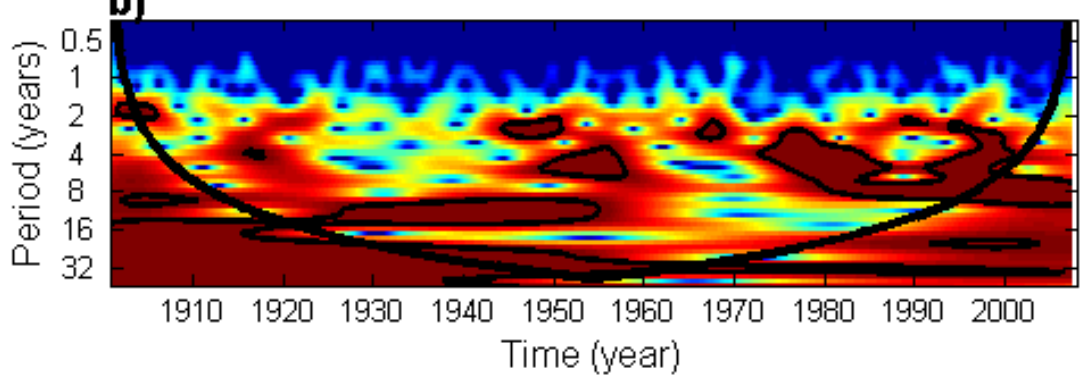

c)
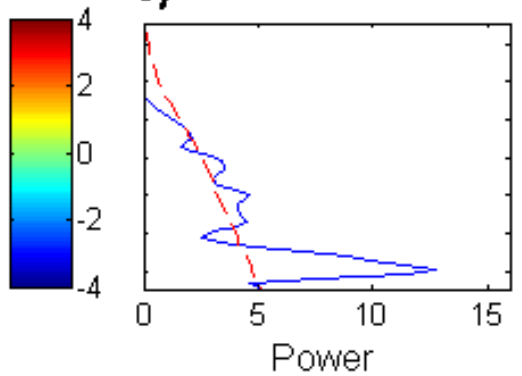

Figure 7. Morlet wavelet of MAC PC2 amplitude.

season in the annual cycle of east African region.

\section{Variability of MAC amplitude}

The instantaneous amplitudes of the MAC leading PC series, their wavelet power spectrum and global wavelet spectrum are displayed in Figures 6 and 7. The time scores of the first mode (Figure 6a) exhibits inter-annual variability with high peaks coinciding with years (for example 1951, 1961, 1997, and 2006) of anomalous rainfall events over the region, with most of the extreme amplitude cases positive.

The local and global wavelet spectra of the PC1 series provided in Figure $6 a$ and $b$ show that the most dominant periodicity of the first mode appears to be at about 32 year, however most of its significant spectrum is below the cone of influence (COI) and thus we assume this periodicity results from the edge 'effects' of wavelet analysis algorithm. We therefore consider second 
dominant peak, whose variability is observed at interannual time scales (2 to 5 years), typical of ENSO phenomenon related variability. The concentration of energy within these periods is statistically significant (Figure 6c). The 2 to 5 year period is observed at significant levels for much of the period (1901 to 2007), except from 1920 to 1930.

The second mode time score series, its local and global wavelet spectra are provided in Figure 7. As in the spectrum of the first EOF PC series, we disregard the 32 year cycle due to the same reasons previously. Noticeable in Figure $7 \mathrm{a}$ are the high/low amplitude phases occurring in successive years exhibiting consistently high or low values. For example, dominant negative amplitude anomalies during the period spanning from 1905 to 1920 , followed by a positive phase from 1921 to 1937, then a low phase from 1938 to 1945.

In the period 1940 to 1981 , no particular phase dominated. Towards the end of the $20^{\text {th }}$ century, the positive phase dominated. The local wavelet spectra of Figure $7 \mathrm{~b}$ show variations dominated by peaks whose periods are between 4 to 8 years and 9 to 16 years indicating signals of ENSO and decadal variability, respectively.

Earlier studies (Rodhe and Virji, 1976; Ropelewski and Halpert, 1987; Ogallo et al., 1994) have also shown the existence of oscillatory peaks in East African rainfall of 2 to 8 years. The decadal signal is found in this study is however only significant from 1920 to 1955.

\section{Conclusion}

EEMD is a useful tool in decomposition of time series in which linearity and stationarity is not guaranteed. The success of EEMD in isolating seasonality components of East African rainfall is shown by the mean EOF PC series of MAC that captures the principal rain seasons over the region, namely: March to May (MAM) and October to December (OND); and the unimodal rainfall regime in the southern part of the region. MAC contributes 45 to $80 \%$ of the proportion of rainfall variability in individual locations over the region with the highest proportion of variability in areas dominated by the annual component of seasonal cycle. The first two MAC modes expressing annual and semi-annual components of seasonality, explains $80 \%$ of the variance of MAC, with the annual (semi-annual) component explaining 58\% (22\%).

Spatial structure of MAC EOF modes reveal that seasonality of rainfall over the whole region does not follow the north/south classical scheme where the semiannual component dominates the equatorial, while the annual component dominates areas relatively far from the equator. This scenario is only true for the western portion of the region $\left(29\right.$ to $\left.35^{\circ} \mathrm{E}\right)$, where the annual component dominates areas that are north/south of $2^{\circ} \mathrm{N} / \mathrm{S}$ of the equator while the semi-annual component dominate the areas within $1^{\circ}$ north/south of the equator. This can be explained by the effects of the complex topographic patterns, the existence of large lakes and land-ocean contrast which creates localized circulations (Anyah and Semazzi, 2004; Okeyo, 1987; Mukabana and Pielke, 1996) leading to receipt of rainfall over highland areas in most months of the year, for example the lake Victoria land/lake breeze and the eastern highland induced upslope/downslope circulation.

MAC amplitude tends to be high during anomalous rainfall, with high/low amplitudes occurring in successive years indicating that the impact of major climate processes that produce seasonal cycle can be amplified or suppressed by interannual to longer timescale variability modes.

Previous studies (Rodhe and Virji, 1976; Nicholson and Entekhabi, 1986) have linked the 2 to 8 years periodicity of east African rainfall to the El Niño - southern oscillation (ENSO), which is the most coherent interannual signal in the global climate.

Indian Ocean dipole (IOD) is another mode of variability which has been shown to modulate the regional rainfall within the range of these periodicities.Previous studies have shown that Indian Ocean sea surface temperatures (SST) anomalies are the dominant factor controlling East Africa short-rains (Latif et al., 1999; Goddard and Graham, 1999; Black et al., 2003; Clark et al., 2003; Behera et al., 2005).

From the wavelet analysis of the instantaneous amplitude of the leading MAC PC series, the years with extreme anomalies and high spectral power such as $1961,1963,1997$ and 2006 coincided with the years of IOD events over the Indian Ocean. In most of these years the IOD co-occurred with the ENSO events in the Pacific Ocean except in 1961 in which one of the strongest IOD events that led to extreme floods over the region occurred.

The 1961 to 1962 rains caused rapid rises in the levels of East African lakes. Lake Victoria rose $2 \mathrm{~m}$ in little more than a year (Conway, 2002; Flohn, 1987). This was not an ENSO year, but exceedingly high sea surface temperatures (SSTs) occurred in the nearby Indian Ocean as well as the Atlantic. The severe El-Nino related floods of 1997/1998, the most severe in the last 50 years, was also enhanced by unusual pattern of SST in the Indian Ocean (IPCC, 2007).

Previous studies on climate anomalies over the region have indicated that the East African rainfall anomalies during December to January 1997/1998 were not only forced by the record $1997 \mathrm{El} \mathrm{Nino,} \mathrm{the} \mathrm{large} \mathrm{buildup} \mathrm{of}$ SSTs over the Indian Ocean also played a role in producing the anomalies in rainfall (Goddard and Graham, 1999; Latif et. al., 1999).

We note that the definition of modulated annual cycle (MAC) by the semi-annual and annual components of rainfall variability could not capture the trimodal regimes experienced in some areas in the study domain. In derivation of MAC for specific locations with trimodal 
rainfall regime, the 4-month mode can be included to capture the trimodal regime for specific location analysis.

This study has shown variability in the seasonal cycle of East African rainfall on interannual-to-longer time scales, which should be considered in studies on variability of rainfall and in seasonal- to-longer time scale prediction of rainfall over the region. Since the modulated annual cycle (MAC) has been shown to capture the spatial and temporal rainfall seasonality structures over the region, it can be used in the assessment of performance of climate models in capturing the seasonality of rainfall over the region.

\section{ACKNOWLEDGEMENTS}

The first author of this study is supported by the Chinese Scholarship Council (CSC) and the Government of Kenya through the National Council for Science and Technology (NCST). The Matlab software was used for the implementation of the EEMD algorithm and Wavelet analysis in this study.

\section{REFERENCES}

Anyah RO, Semazzi FH M (2004). Simulation of the response of Lake Victoria basin climate to lake surface temperatures. Theor. Appl. Climatol., 79: 55-69.

Behera SK, Luo J, Masson S, Yamagata T, Delecluse P, Gualdi S, Navarra A (2005). Paramount Impact of the Indian Ocean Dipole on the East African Short Rains: A CGCM Study. J. Clim., 18: 45144530.

Black E, Slingo J, Sperber KR (2003). An observational study of the Relationship between Excessively Strong Short Rains in Coastal East Africa and Indian Ocean SST. Mon. Weather Rev., 131: 74-94.

Clark CO, Webster PJ, Cole JE (2003). Interdecadal variability of the relationship between the Indian Ocean Zonal Mode and East African coastal rainfall anomalies, J. Clim., 16: 548-554.

Beltrando G (1990). Space time variability of rainfall in April and October - November over East Africa during the period 1932-83. Int. J. Climatol., 10: 691-702.

Bograd S, Schwing F, Mendelssohn R, Green-Jessen P (2002). On the changing seasonality over the North Pacific. doi: 10.1029/2001GL013790.Geophys Res.Lett., 29: 1333,

Bowden J, Semazzi FHM (2007). Empirical analysis of intraseasonal climate variability over the Greater Horn of Africa. J. Climate, 20(23): 5715-5731.

Camberlin P, Philippon N (2002). The East African March-May rainy season: Associated atmospheric dynamics and predictability over the 1968-97 period. J. Clim., 15: 1002-1019.

Conway D (2002). Extreme rainfall events and lake level changes in East Africa: recent events and precedents. In the East African Great Lakes: Limnology, Paleoclimatology and Biodiversity, Odada EO, Olago DO (eds). Advances in Global Change Research, Vol. 12 Kluwer: Dordretcht.

Davies TD, Vincent CE, Beresford AKC (1985). July-August rainfall in west-central Kenya. Int. J. Climatol. 5: 17-33.

Flohn H (1987). East African rains of 1961/62 and the abrupt change of the White Nile discharge: Paleoecology of Africa and surrounding Islands, 18: 3-18.

Goddard L, Graham NE (1999). The importance of the Indian Ocean for simulating Rainfall Anomalies over Eastern and Southern Africa, J. Geophys. Res., 104: 19099-19116.

Hastenrath S, Polzin D, Mutai CC (2007). Diagnosing the 2005 Drought in equatorial East Africa. J. Clim., 20: 4628-4637.

Huang NE, Shen Z, Long SR, Wu MC, Shih HH, Zheng Q, Yen N, Tung CC, Liu HH (1998). The empirical mode decomposition method and the Hilbert spectrum for non-stationary time series analysis. Proc. R. Soc. London, 454A: 903-995.

Huang NE, Wu Z (2008). A review on Hilbert-Huang Transform: the method and its applications on geophysical studies. Rev. Geophys. 46: RG2006, doi: 10.1029/2007RG000228.

Indeje M, Semazzi FHM, Ogallo LJ (2000). ENSO signals in East African rainfall and their prediction potentials. Int. J. Climatol., 20: 1946.

IPPC (2007). Climate Change 2007: Impacts,Adaptation and Vulnerability. Contribution of Working Group II to the Fourth Assessment. Report of Intergovernmental Panel on Climate Change ML, Parry OF, Canziani JP, Palutikof PJ, van der Linden and Hanson CE (Eds.), Cambridge University Press, Cambridge, UK.

Jury MR, Mpeta EJ (2009). African climate variability in the satellite era. Theor. Appl. Climatol., 98: 279-291.

Kim D, Oh HS (2009). EMD: A package for Empirical Mode Decomposition and Hilbert Spectrum. R. J., 1(1): 40-46.

Latif M, Dommenget D, Dima M (1999). The role of Indian Ocean sea surface temperature in forcing east African climate anomalies during winter 1998. J. Climate, 12: 3479-3504.

Mukabana JR, Pielke RA (1996). Investigating the influence of synopticscale monsoonal winds and meso-scale circulations on diurnal weather patterns over Kenya using a mesoscalenumerical model. Mon. Wea. Rev. 124: 224-243.

Mutai CC, Ward MN (2000). East African rainfall and the tropical circulation/convection on intra-seasonal to interannual timescales. J. Clim., 13: 3915-3939.

Mutai CC, Ward MN, Colman AW (1998). Towards the prediction of East African short rains based on sea surface temperature-atmosphere coupling. Int. J. Climatol., 17: 117-135.

Niazy RK, Beckmann CF, Brady JM, Smith SM (2009). Performance evaluation of the ensemble empirical mode decomposition. J. Adv. Adapt.Data Anal., 1(2): 231-242.

Nicholson SE (2001). A semi-quantitative regional data set for studying African climate of the nineteenth century, Part 1. Overview of the data set. Clim. Chang., 50: 317-353.

Nicholson SE (1996). A review of climate dynamics and climate variability in eastern Africa. The Limnology, Climatology and Paleoclimatology of the East Africa Lakes, Johnson TC,OdadaE(Eds.) Gordon and Breach, pp. 25-56.

Nicholson SE, Entekhabi D (1986). Rainfall variability in Equatorial and Southern Africa Relationship with the sea surface temperature along the southeast coast of Africa. J. Appl. Meteor. Clim., 26: 561-578.

Nyenzi BS (1992). An analysis of the interannual variability of rainfall over East Africa. J. Afr. Met. Soc., 1: 57-79.

Pezzulli S, Stephenson DB, Hannachi A (2005). The variability of seasonality. J. Clim., 18: 71-88.

Ogallo LJ, Okoola RE, WanjohiDN (1994). Characteristics of quasibiennial oscillation over Kenya and their predictability potentials for seasonal rainfall. Mausam 45 (1): 57-62.

Ogallo LJ (1982). Quasi-periodic patterns in East African rainfall records. Kenya J. Sci. Technol., A3: 43-54.

Okeyo AE (1987). The influence of Lake Victoria on the convective activities over the Kenya Highlands. J. Meteor. Soc. Jpn., 65: 689695.

Owiti ZO, Ogallo LA, Mutemi J (2008). Linkages between the Indian Ocean Dipole and east African seasonal rainfall anomalies. J. Kenya Meteor. Soc., 2: 3-17.

Okoola RE, Camberlin P, Ininda JM (2008). Wet periods along East African coast and the extreme wet spell event of October 1997. J. Kenya Meteor. Soc., 2: 67-83.

Parker D, Good E, Chadwick R (2011). Reviews of observational data availability over Africa, for monitoring, attribution and forecast evaluation. Met Office, Hadley Center Technical Note, p. 86.

Qian S (2002) Introduction to Time-Frequency and Wavelet Transforms. Prentice-Hall Inc Upper Saddle River, NJ., pp. 41-42.

Qian C, Wu Z, Fu C, Zhou T (2010). On multi-timescale variability of temperature in China in modulated annual cycle reference frame. Adv. Atmos. Sci. DOI: 10.1007/s00376-009-9121-4. 
Qian C, Fu CB, Wu Z, Yan ZW (2011). The role of changes in the annual cycle in earlier onset of climatic spring in northern China. Adv. Atmos. Sci., 28(2): 284-296, doi: 10.1007/s00376-010-9221-1.

Rodhe H, Virji H (1976). Trends and periodicities in East African rainfall. Mon. Wea. Rev., 104: 307-315.

Ropelewski CF,HalpertMS (1987). Global and regional scale precipitation patterns associated with the El Niño/Southern Oscillation. Mon. Weather Rev., 115: 1602-1626.

Schreck CJ III, Semazzi FHM (2004). Variability of the recent climate Eastern Africa. Int. J. of Climatol. 24: 681-701.

Segele ZT, Lamb PJ, Leslie LM (2009).Seasonal-to-interannual variability of Ethiopia/Horn of Africa Monsoon. Part I: Association of Wavelet-Filtered large scale atmospheric circulation and global ocean surface temperature. J. Clim., 22: 3396-3421.

Shen SP, Shu T, Huang NE, Wu Z, North GR, Carl TR, Easterling DR (2005).HHT analysis of the nonlinear and non-stationary annual cycle of daily surface air temperature data. In: Huang NE, Shen SSP (eds). Hilbert-Huang transform: introduction and applications. World Scientific, Singapore, pp. 187-210.

Shongwe ME, van Oldenborgh van Aalst (2011). Projected changes in mean and extreme precipitation in Africa under global warming, Part II: East Africa. J. Clim., 24: 3718-3731.

Thompson R (1999). A time-series analysis of the changing seasonality of precipitation in the British Isles and neighbouring areas. J. Hydrol., 224: 169-183.

Torrence C, Compo GP (1998). A practical guide to wavelet analysis, Bull. Am. Meteor. Soc., 79: 61-79.
Webster PJ, Moore AM, Loschigg JP, Leben RR (1999). Coupled ocean-atmosphere dynamics in the Indian Ocean during 1997/98. Nature, 401: 356-360.

Whitfield PH, Bodtker K, Cannon AJ (2002). Recent variations in temperature and precipitation in Canada, 197695. Int. J. Climatol., 22: 1617-1644.

Willmott P, Matsuura K (2009). A revised 100-year plus gridded time series of monthly precipitation and air temperature for the global land surface: Monthly time series (1900-2008) Version 2.0 1. [Available online at http://climate.geog.udel.edu/climate]. Website accessed on 25 July, 2011.

Wu Z, Huang NE (2009). Ensemble Empirical Mode Decomposition: a noise-assisted data analysis method. Adv. Adapt. Data Anal., 1: 1-41.

Wu Z, Schneider EK, Kirtman BP, Sarachik ES, Huang NE, Tucker CJ (2008). Amplitude-frequency modulated annual cycle: an alternative reference frame for climate anomaly. Climate Dynamics DOI 10.1007/s00382-008-0437-z.

Zhaohua W, Huang NE (2004). A study of the characteristics of white noise using the empirical mode decomposition method. R. Soc. Lond., 460: 1597-1611. 